\title{
Radar Measurement of Waves and Currents in the Nearshore Zone
}

\author{
Stephen Frasier \\ Electrical \& Computer Engineering \\ Knowles Engineering Bldg., Rm. 113 \\ University of Massachusetts \\ Amherst, MA 01003 \\ phone: (413) 545-4582 fax: (413) 545-4652 email: frasier@ecs.umass.edu \\ Grant Number(s): N00014-02-1-0239, N00014-07-1-0337 \\ http://www.umass.edu/mirsl
}

\section{LONG-TERM GOALS}

Our long-term goal is to contribute to the understanding of the upper ocean and lower atmosphere through the development and application of novel microwave, acoustic, and optical remote sensing techniques.

\section{OBJECTIVES}

The objectives of this effort are to determine the extent to which Doppler radar techniques can be exploited for both qualitative and quantitative nearshore measurement applications. Of particular interest are estimates of surf zone location, extent, surface currents, and wave parameters. To date, optical (video) techniques have been the primary remote sensing technology for these applications. An advantage of radar is its all-weather, day-night operability.

\section{APPROACH}

We deployed two Doppler radar systems adapted from commercial high-seas navigation radars during the 2003 Nearshore Canyon Experiment (NCEX). The modified marine radars systems were deployed during NCEX to provide synoptic images of the incident wave fields and surface currents through measurement of backscattered power and Doppler velocities. This work continues prior efforts using the FOPAIR imaging radar to further our understanding of radar backscatter from nearshore breaking waves and inter-bore processes (Puleo et al., 2003; Farquharson et al., 2005).

During NCEX, one radar was deployed atop the NOAA Southwest Fisheries Science Center, and the other above the Black's Beach access road. Both time-resolved and time-averaged radar imagery are analyzed to deduce nearshore properties with intercomparisons with available in-situ and video observations. Our analysis efforts focus on the first three moments of the Doppler spectrum: backscattered power, mean Doppler velocity, and Doppler spectrum width. Finally, our experience with modifying commercial marine radars for NCEX has also motivated development of a truly coherent low-peak-power Doppler radar for nearshore applications.

\section{WORK COMPLETED}

We have compared radar measurements of surface velocity obtained through the Doppler signature with video observations of surface currents obtained from Particle Image Velocimetry techniques. Radar and 


\section{Report Documentation Page}

Form Approved

OMB No. 0704-0188

Public reporting burden for the collection of information is estimated to average 1 hour per response, including the time for reviewing instructions, searching existing data sources, gathering and maintaining the data needed, and completing and reviewing the collection of information. Send comments regarding this burden estimate or any other aspect of this collection of information,

including suggestions for reducing this burden, to Washington Headquarters Services, Directorate for Information Operations and Reports, 1215 Jefferson Davis Highway, Suite 1204, Arlington

VA 22202-4302. Respondents should be aware that notwithstanding any other provision of law, no person shall be subject to a penalty for failing to comply with a collection of information if it

does not display a currently valid OMB control number.

\begin{tabular}{|c|c|c|}
\hline $\begin{array}{l}\text { 1. REPORT DATE } \\
\mathbf{2 0 0 7}\end{array}$ & 2. REPORT TYPE & $\begin{array}{l}\text { 3. DATES COVERED } \\
\mathbf{0 0 - 0 0 - 2 0 0 7} \text { to 00-00-2007 }\end{array}$ \\
\hline \multirow{3}{*}{\multicolumn{2}{|c|}{$\begin{array}{l}\text { 4. TITLE AND SUBTITLE } \\
\text { Radar Measurement of Waves and Currents in the Nearshore Zone }\end{array}$}} & 5a. CONTRACT NUMBER \\
\hline & & 5b. GRANT NUMBER \\
\hline & & 5c. PROGRAM ELEMENT NUMBER \\
\hline \multirow{3}{*}{\multicolumn{2}{|c|}{ 6. AUTHOR(S) }} & 5d. PROJECT NUMBER \\
\hline & & 5e. TASK NUMBER \\
\hline & & 5f. WORK UNIT NUMBER \\
\hline \multicolumn{2}{|c|}{$\begin{array}{l}\text { 7. PERFORMING ORGANIZATION NAME(S) AND ADDRESS(ES) } \\
\text { University of Massachusetts,Electrical \& Computer Engineering,Knowles } \\
\text { Engineering Bldg., Rm. 113,Amherst,MA,01003 }\end{array}$} & $\begin{array}{l}\text { 8. PERFORMING ORGANIZATION } \\
\text { REPORT NUMBER }\end{array}$ \\
\hline \multirow{2}{*}{\multicolumn{2}{|c|}{ 9. SPONSORING/MONITORING AGENCY NAME(S) AND ADDRESS(ES) }} & 10. SPONSOR/MONITOR'S ACRONYM(S) \\
\hline & & $\begin{array}{l}\text { 11. SPONSOR/MONITOR'S REPORT } \\
\text { NUMBER(S) }\end{array}$ \\
\hline
\end{tabular}

12. DISTRIBUTION/AVAILABILITY STATEMENT

Approved for public release; distribution unlimited

13. SUPPLEMENTARY NOTES

14. ABSTRACT

15. SUBJECT TERMS

16. SECURITY CLASSIFICATION OF:

\begin{tabular}{c|c|c}
$\begin{array}{c}\text { a. REPORT } \\
\text { unclassified }\end{array}$ & $\begin{array}{c}\text { b. ABSTRACT } \\
\text { unclassified }\end{array}$ & $\begin{array}{c}\text { c. THIS PAGE } \\
\text { unclassified }\end{array}$
\end{tabular}

17. LIMITATION OF ABSTRACT

Same as

Report (SAR)
18. NUMBER 19a. NAME OF

OF PAGES RESPONSIBLE PERSON

8 
merged video images from three Ohio State University video cameras have been rectified to a common coordinate system with the positive $\mathrm{x}$-axis pointing East and positive $\mathrm{y}$-axis pointing North, origin located at the piling number three at the Scripps Institution of Oceanography (SIO) pier. The analysis of radar data suggests that even in low wind conditions microwave radar is sensitive to low-grazing angle scattering from mechanically generated surface roughness in the surf zone, and that the surf zone width is thus easily identified in almost any environmental condition. The comparisons of mean surface longshore flows suggest that both radar and video observe the true surface current with small biases.

A manuscript was completed and submitted for review to JGR Oceans detailing the comparison of PIV video and Doppler radar mean longshore current over $1 \mathrm{~km}$ stretch of the Black's beach in La Jolla, CA on 31 October 2003. We have also made available radar imagery and radar data (netCDF format) and posted to our NCEX web archive at http://abyss.ecs.umass.edu/ncex/. Design and testing of the low-power solid-state coherent Doppler radar was completed in winter of 2007 ([Perkovic, 2006]).

\section{RESULTS}

Figure 1(a) shows a 9-minute time-averaged image of radar backscatter over the experiment area. Bright areas indicate regions of strong backscatter while dark areas indicate regions of little or no backscatter. Figure 1(b) shows a video intensity composite image. Radar backscatter is significant in the surf zone even in the absence of wind ([Farquharson, 2005], [Puleo, 2003) since most of the roughness is mechanically generated by breaking waves (rather than solely wind-generated). Similarly, the bright area in the video intensity image is produced by wave breaking in the surf zone. The darker areas are regions where there is no significant breaking.

Figure 2 shows color contour images of 9 minute averaged radar and PIV radial velocity over the region corresponding to the field of view of the video cameras at $1000 \mathrm{hrs}$ PST on 31 October 2003. The velocity scale shown in Figure 2 ranges $+/-1.5 \mathrm{~m} / \mathrm{s}$ and is colored the same in the radar and PIV surface velocity maps. As the radar only measures the radial velocity component from its location, the PIV vector velocity estimates were projected into radar's radial direction for comparison. The location of the radar (and video cameras) is such that the radial velocity is very nearly alongshore at NCEX; thus the velocities shown are essentially longshore currents. The grid spacing is $5 \mathrm{~m}$ by $5 \mathrm{~m}$. The white region is outside video field of view, on dry beach, or represents missing data in both images. Good agreement between radar and PIV is clearly evident. Similarities of spatially varying longshore current features are clearly visible. At about $1100 \mathrm{~m}$ distance alongshore the surface longshore current reverses direction with southerly flow near the shore (towards the radar; blue color) and northerly flow (away from the radar; red color). This feature is suggestive of a strong seaward flowing current and eddy-like structure at that location. In general, the radar and PIV surface velocity maps agree quite well over the $1 \mathrm{~km}$ alongshore region examined.

When a scatter plot was made for locations that belong strictly to the surf zone, the best fit line for these velocities had a slope of 1.02 (dashed line in Figure 3) very close to the ideal 1:1 slope fit (solid line through the data in Figure 3). The rms difference in velocity values for the surf zone is $0.18 \mathrm{~m} / \mathrm{s}$ while the correlation coefficient squared is 0.79 . Thus, within the surf zone, the longshore velocities observed by both techniques are quantitatively consistent and with small (2\%) bias.

Figure 4 shows a comparison of the longshore current profile along a single transect at the alongshore 
distance of $1140 \mathrm{~m}$. Both PIV and radar velocities show the same form, going from negative (southerly) flow at distances farther offshore to positive (northerly) flow closer to shore. The radar velocities between $130 \mathrm{~m}$ and $170 \mathrm{~m}$ cross-shore distance, are approx. constant at $-0.5 \mathrm{~m} / \mathrm{s}$, whereas PIV velocities range smoothly from $-0.9 \mathrm{~m} / \mathrm{s}$ at $120 \mathrm{~m}$ to $-0.5 \mathrm{~m} / \mathrm{s}$ at $170 \mathrm{~m}$ peaking at about $-1.0 \mathrm{~m} / \mathrm{s}$ at cross-shore location $140 \mathrm{~m}$. Also, PIV velocities peak at a higher northerly flow $(1.0 \mathrm{~m} / \mathrm{s})$ at $230 \mathrm{~m}$ cross-shore distance, and between $240 \mathrm{~m}$ and $280 \mathrm{~m}$ cross-shore distance the radar and PIV velocities track each other closely. Video-derived estimates of the mean surf zone width on this transect indicate that the edge of the surf zone is located at approximately $154 \mathrm{~m}$ cross-shore distance and labeled by the dashed line in Figure 4, placing most of the divergent velocity points near the seaward breaker line. The approximate position of the shoreline (estimated from the intersection of mean sea level with the foreshore beach profile) is shown with the other dashed line in Figure 4.

Surf zone extent is estimated from video data using time-stacking technique and contrast of visible features. The same parameter is inferred from radar data using edge detection on the average radar backscatter images. Since the backscatter from breaking waves greatly exceeds that from offshore areas due to increased surface roughness produced by mechanical breaking of waves, the surf zone is easily detectable in radar images by means of an edge filter. Figure 5(a) shows the surf zone width as estimated by radar (solid line) and video (dashed line) using two different detection techniques over a period of approx. 24 hours on 31 October 2003 at alongshore distance of $1000 \mathrm{~m}$. The tide level as measured at the SIO pier is shown in Figure 5(b). As expected, the width of the surf zone follows a tide trend, being wider at higher tide and narrower at low tide. The video estimates were available only during the daylight hours and hence make the comparison possible at times of mid to high tide.

\section{IMPACT/APPLICATIONS}

The work presented describes the first detailed comparison of mean longshore surface current estimation between Doppler radar velocities and PIV video velocities. These results will aid in interpretation of microwave radar measurements in the nearshore region. Furthermore, the measurements of surf zone width made during NCEX may be used to aid model and prediction development of the nearshore surface mean flows over complex bathymetry at times when these estimates were not available from video techniques.

\section{TRANSITIONS}

None

\section{RELATED PROJECTS}

None 


\section{PUBLICATIONS}

Perkovic, D., T. C. Lippmann, and S.J. Frasier, 2007 (submitted). "Longshore Surface Currents Measured by Doppler Radar and Video PIV Techniques", J. Geophys. Res.

\section{REFERENCES}

Farquharson, G., S.J. Frasier, B. Raubenheimer, and S. Elgar, 2005. "Microwave Radar Cross Sections and Doppler Velocities Measured from the Surf Zone", J. Geophys. Res., 110(C12), doi:10.1029/-2005JC003022.

Puleo, J.A., G. Farquharson, S.J. Frasier, and K.T. Holland, 2003. "Comparison of optical and radar measurements of surf and swash zone velocity fields", J. Geophys. Res., 108(C3), 3100, doi:10.1029/ 2002JC001483.

Perkovic, D., G. Pathak and S.J. Frasier, 2006. "Comparison of optical and radar measurements of surf and swash zone velocity fields”, EOS Trans. AGU, 87(36), Ocean Sci. Meet. Suppl., Abstract OS340-06. 


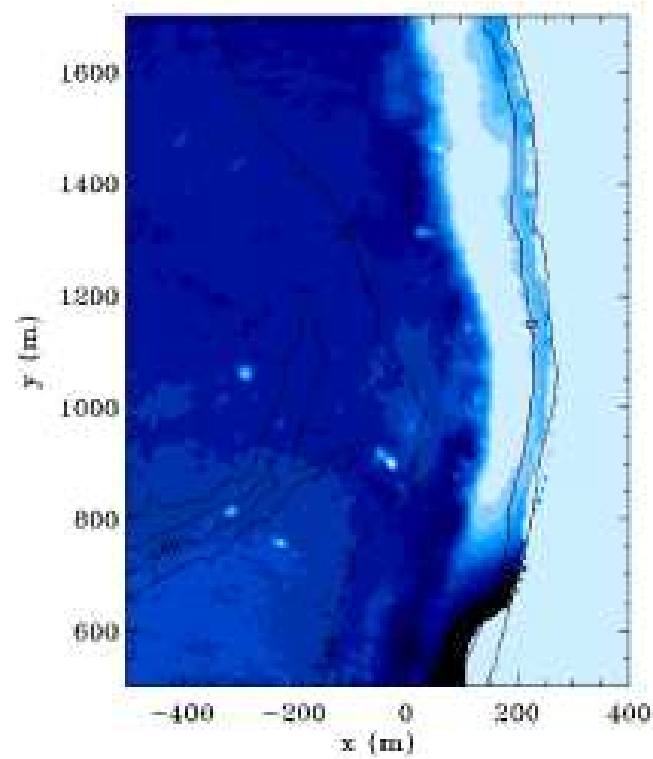

(a)
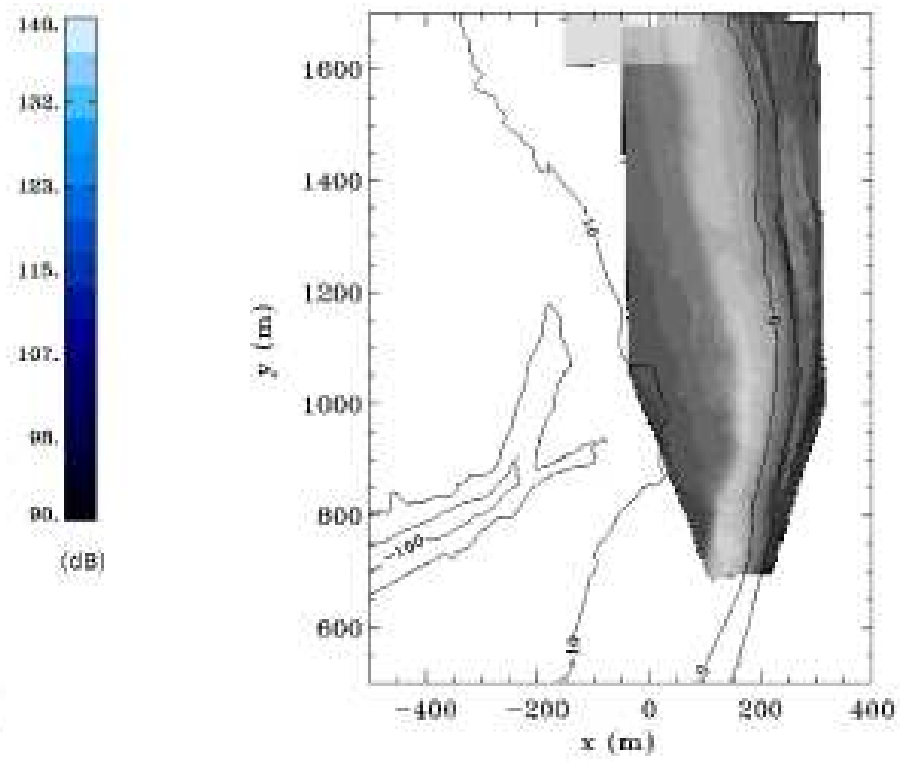

(b)

Figure 1: Data from 31 October 2003 at 1000 hrs PST. Depth contours are shown in meters relative to MSL. Offshore is to the left and the shoreline is between the 0 and $1 \mathrm{~m}$ contour lines. (a) Nine minute time average of range-corrected radar echo indicating strong echo from the surf zone. Point echoes offshore are due to buoys deployed around Scripps canyon. (b) Nine minute merged video intensity from Ohio State video cameras also showing surf zone extent. 


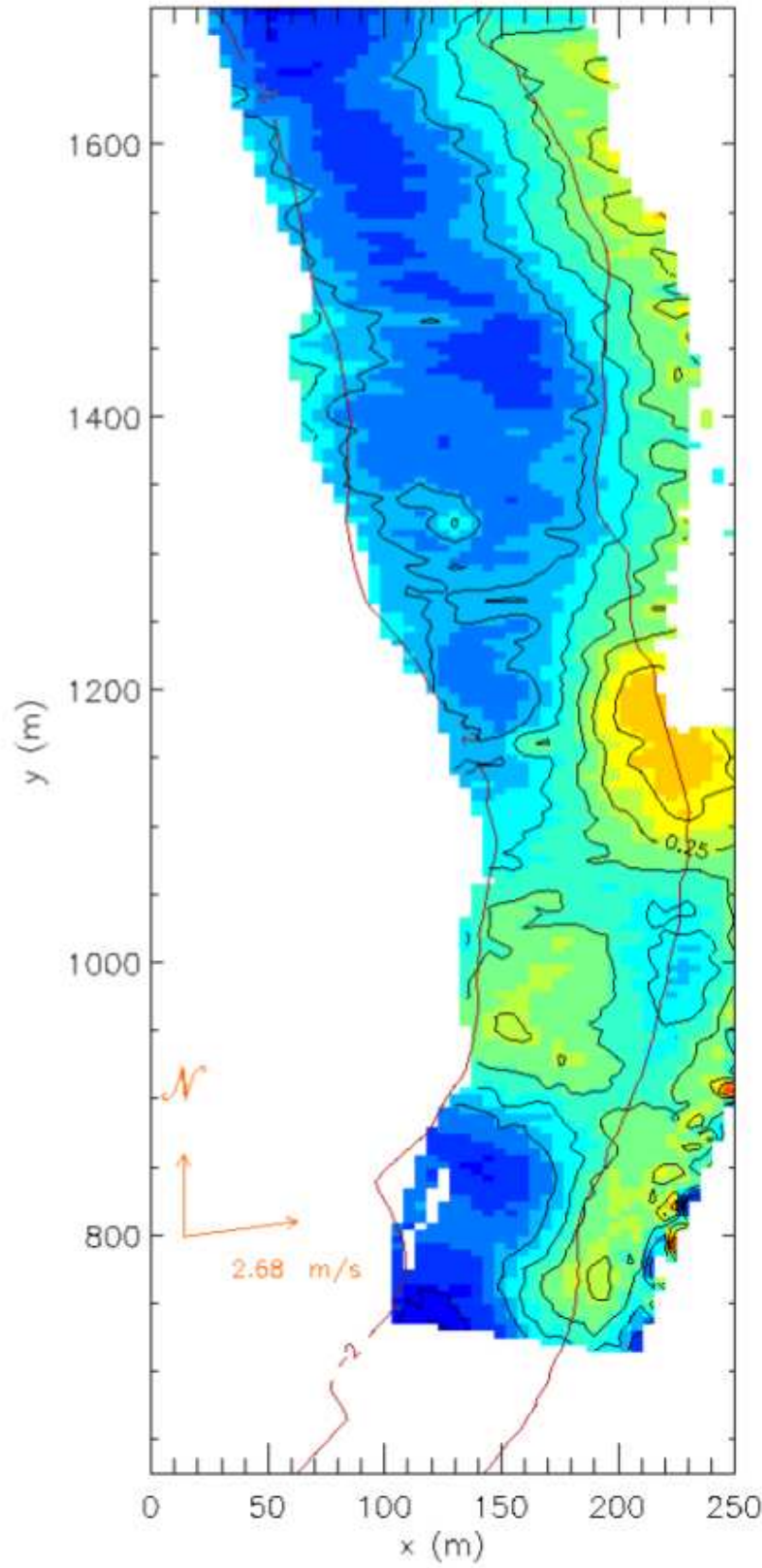

(a)

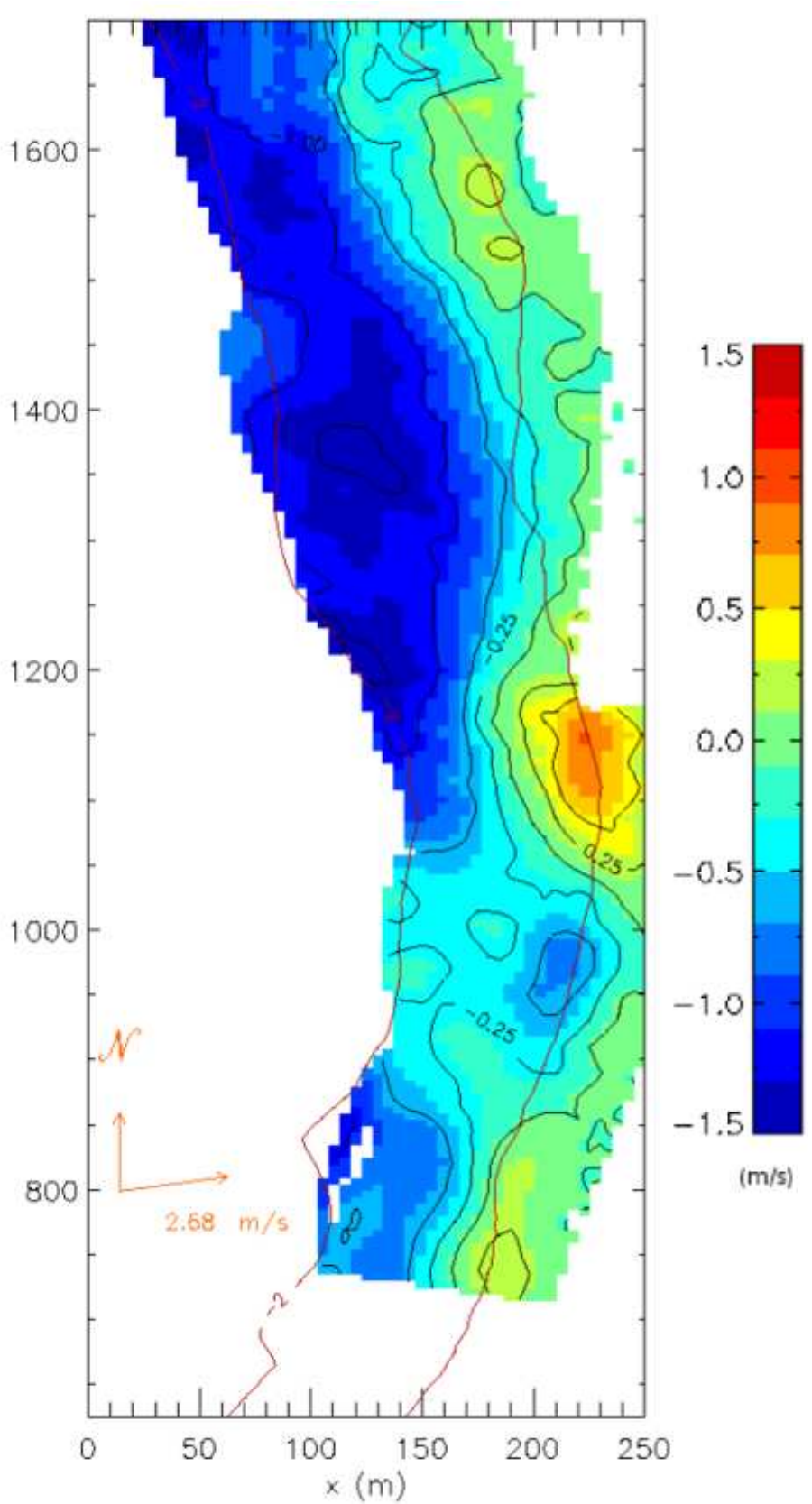

(b)

Figure 2: Nine minute averaged radial (approximately longshore) surface velocity starting at 1000 hrs PST, 31 October 2003, along Black's beach, La Jolla, CA (a) Radar Doppler radial velocity. (b) Video PIV radial velocity. Velocity magnitudes are shown by the color bar on the r.h.s. wind direction and magnitudes are shown with the direction arrows relative to true North in the bottom left. 


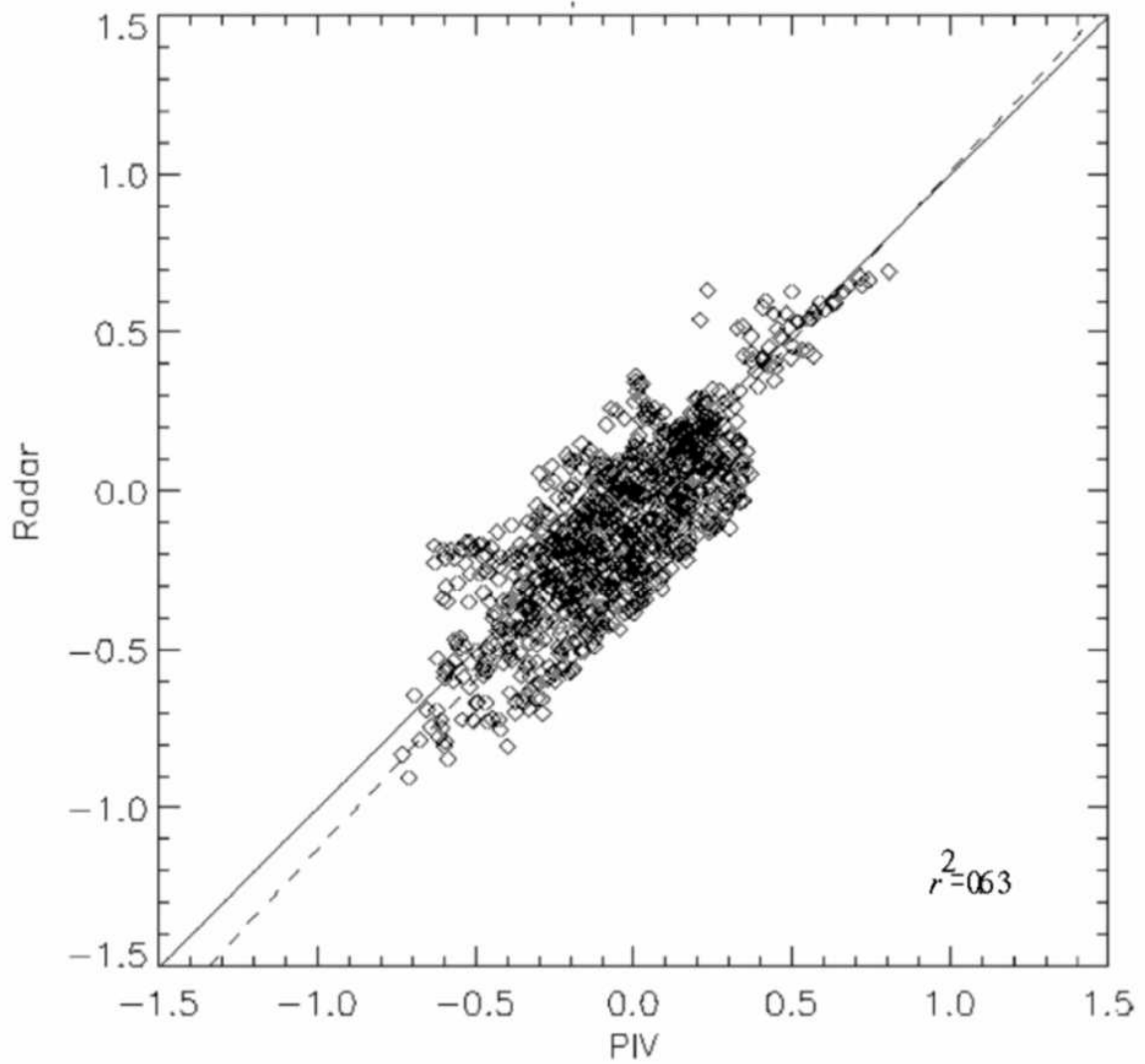

Figure 3: Scatter plot of radar Doppler velocities vs. corresponding PIV radial velocities over the surf zone alone. The correlation coefficient squared is 0.63 


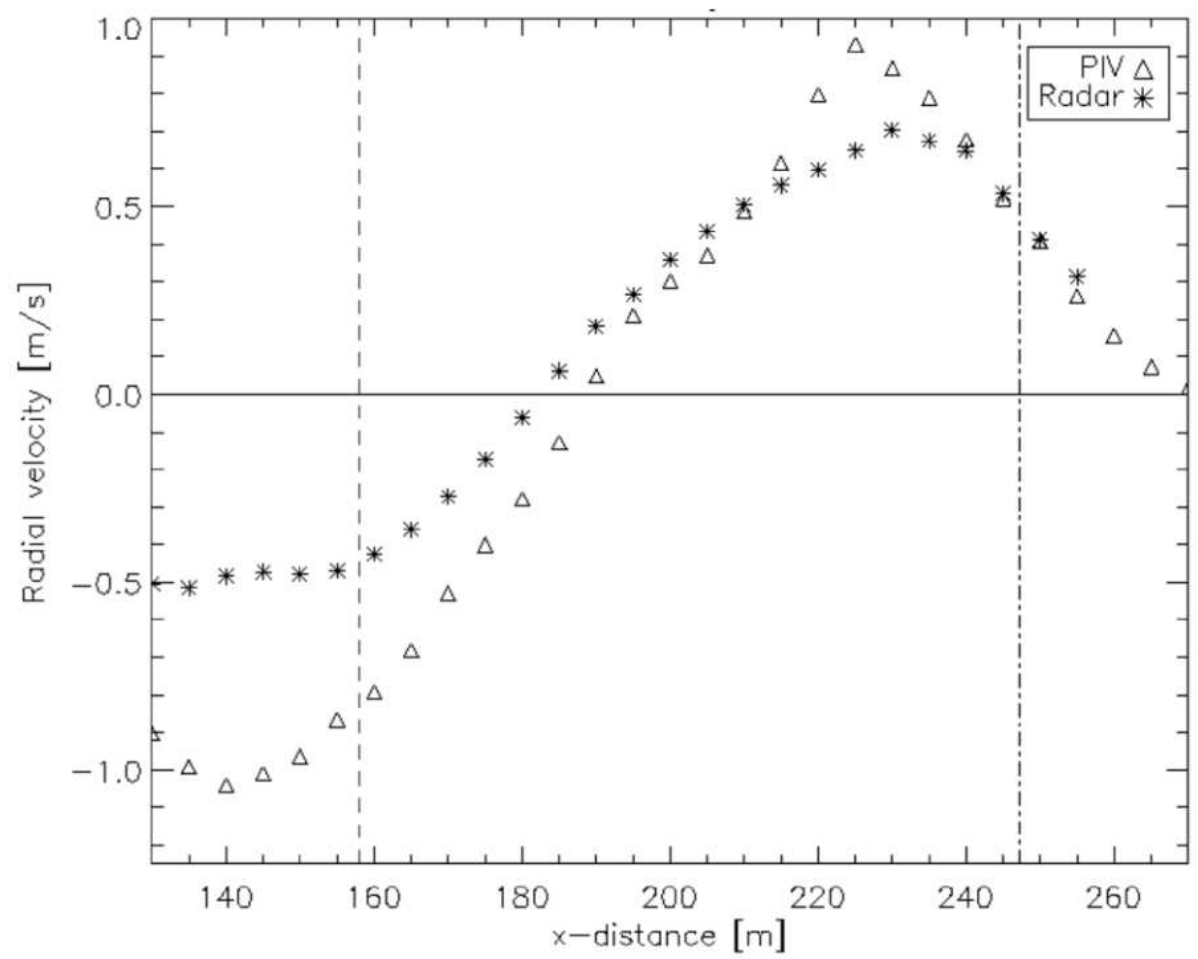

Figure 4: Cross-shore transect of Doppler and PIV velocities at $1140 \mathrm{~m}$ alongshore. Velocity estimates are 9 minute averages. Dashed line on the left marks the inner edge of the breaker zone, the dotdashed line on the right marks the outer edge of the swash zone.
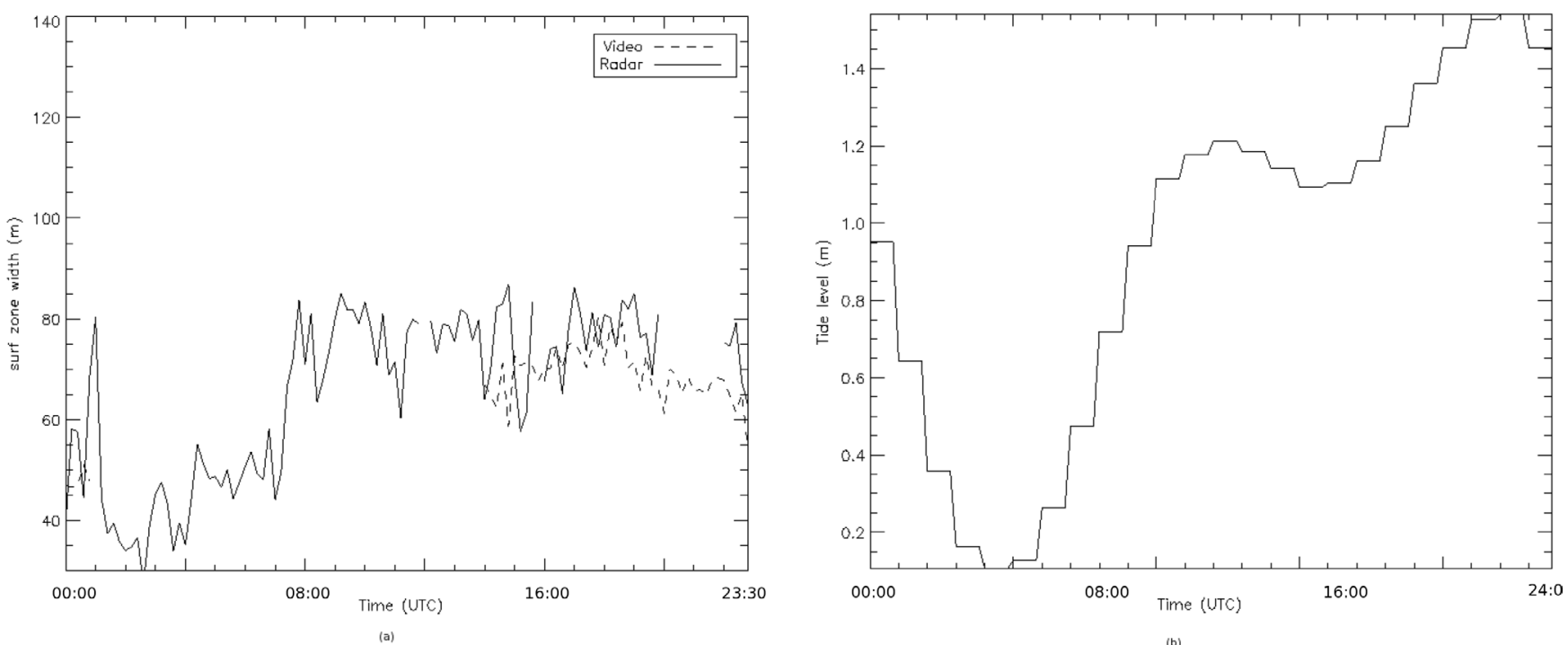

Figure 5: (a) Nine minute estimates of the surf zone width at $1000 \mathrm{~m}$ alongshore distance on 31 October 2003 estimated by the radar (solid line) and video (dashed line). (b) Tide level at the SIO pier measured at hourly intervals. 